BROOKHAVEN NATIONAL LABORATORY

Associated Universities, Inc.

Upton, New York

ACCELERATOR DEPARTMENT

Informal Report

\title{
A MULTIPARTICLE DETECTOR FOR ISABELLE
}

J. Kirz, Stony Brook

January 1974

This report was prepart as an account of work
sponsored py the United States Government. Neither
the United ates nor the United States Aromic Energy
Commission. nor any of their employees, nor any of
their contractors, subcontractors, or their employees,
mokes any warranty, express or implied, or assumes any
legal liahility or responsibility for the accurisy, com-
pleteness or usefulness of any information, apparatus,
product or process disclosed, or represents that its use
would not infringe privately owned rights.

NOTICE

This report was prepared as an account of work sponsored by the United States Government. Neither the United States nor the United States Atomic Energy Commission, nor any of their employees, nor any of their contractors, subcontractors, or their employees, makes any warranty, express or implied, or assumes any legal liability or responsibility for the accuracy, completeness or usefulness of any information, apparatus, product or process disclosed, or represents that its use would not infringe privately owned rights. 


$$
\text { I. K1rz, Stony Brook Nov. } 1973 .
$$

The proposed multiparticle spectrometer is designed to study particles produced at small angles $(0.5 \div \theta<20 \mathrm{mr})$. It is assumed to be part of a larger set-up, where the larger angles are covered by other spectrometers, or at least a $4 \pi$ detector, such as described by Amold et al. (CRISP 72-65).

The genfral layout consists of 4 magnets in a symmetrical arrangemenc, as shown on Fig. 1. Magnet $B_{1}$ introduces dispersion, while $B_{2}$ compensates for $1 t$. A set of proportional chembers downstream from $B_{2}$ can measure both angle and momentum. The apparatus may in fact end here, however, using a second pair of nagnets $B_{3}$ and $B_{4}$ the momenta can be re-combined. Then all tracks will point back to the original interaction point in compact bundle, which may be suitable for particle identification by Cerenkov counters further downstream. 1

\section{Acceptance and Resolution.}

Downstream of $B_{2}$ the displacement for particles produced at $0^{\circ}$ is $5 \frac{\text { Po }}{\mathrm{P}} \mathrm{cm}$. The divergence due to finite production angle is to be added to this. We assume that the vacuum tank allows particle detection starting $1 \mathrm{~cm}$ from the nominal beam center. Then the acceptance in $X$ vs $P_{\perp}$ space is shown on Fig. 2. The upper 1imit in $P_{\perp}$ is determined by the width of the magnet-gap. 


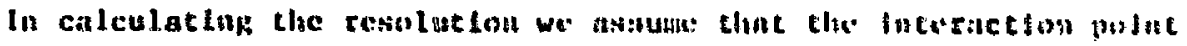
can be used in track reconstruction, and that it is determined to wh thin \pm 2 in the transverse directions. Then with $\ln$ resolution in the proportional chambers, we get $\frac{\Delta P}{P} \approx \pm 4 x$ at $200 \mathrm{GeV} / \mathrm{e}, 0.4 \%$ at $20 \mathrm{GeV} / \mathrm{c}$. Using two sets of proportional cluabers behind $B_{2}$. 3m apart, the production angle is determined to $30 \approx 0.5 \mathrm{mr}$. $A$ hetter meastarenent can be made with the four-magnet system behind $b_{4}$, where if the freagaction point is usod, one gets $10 \therefore 0.1 \mathrm{mr}$.

MagneEs. Vicuun Slagming.

Each of the proposed magnets has $1 \mathrm{Bdl}=60 \mathrm{kgm}$. To aceppt $20 \mathrm{mr}$ production angle, and 20-200 feV/c momentum bite, the gap dimenslons becone:

$B_{1}: 0.32 \mathrm{~m} \mathrm{high} \times 0.5 \mathrm{~m}$ wide

$B_{2}: 0.56 \mathrm{~m} \mathrm{high} \times 1.5 \mathrm{~m}$ wide

$\mathrm{B}_{3}: 0.8 \mathrm{~m} \mathrm{high} \times 2.75 \mathrm{~m}$ wide

$B_{4}: 1.0 \mathrm{~m} \mathrm{hlgh} \times 1.2 \mathrm{~m}$ wide

Saller gap lieights lead to a proportional decrease in solld angle acceptance, and economy wight dictate cuttug all lieights by a factor of 2 or sa. Thu we st111 have 20 mr in the bending plane, 10 m in the plane prependicular to it.

The vacuub tank w1ll fill $\mathrm{B}_{2}$ and $\mathrm{B}_{2}$. It flares out to contain all particles unt1l they emerge from $0_{2}$. Here a chin utndow allows the partieles to escape into the afr. It is also trere thet the flrst proportional chambers are placed. Out of the whadow como a sall continuation of the vacuum tank ( $\left.12 \times 4 \mathrm{~cm}^{2}\right)$, which contains the two beams, whose centers are bent 
apart by $10 \mathrm{em}$ it this polat ( In addition to the separation due to fintte crossing angle).

Space_and_Luminosicy zeguirgments.

To allow for other desectors ncar the incersection region, we place the first mannet starting at $4.5 \mathrm{sm}$ from the incerscetion polat. This puts the downstream end of $\mathrm{b}_{7}$ at $22.5 \mathrm{~m}$, and allowing 3.5 space to measure angles and momenta, the mindmal treztp ends at abouk 16m. If we add $t_{3}$ ind $b_{4}$, the length grow to $27 \mathrm{~m}$, but in this case furthur space is also necded for Cerenkov counters near the beum - a clear space of 50 total would be destrable on one slde of the intersection.

A very large fraction of the interactions $u 111$ produce partieles which traverse this apparatus. Therefore the requirement is that the luntrosity be set Low enough $\left(\leq 10^{31} \mathrm{~cm}^{-2} \mathrm{sec}^{-1}\right)$.

Fooknote.

(1) It my be useful to use a quidrupole doublet here to rander an single momentu paraled. The use of differential Cerenkov counters may then be an ateractive possfbility: these cen be conolderably shorter in length than the chreshold variety. 


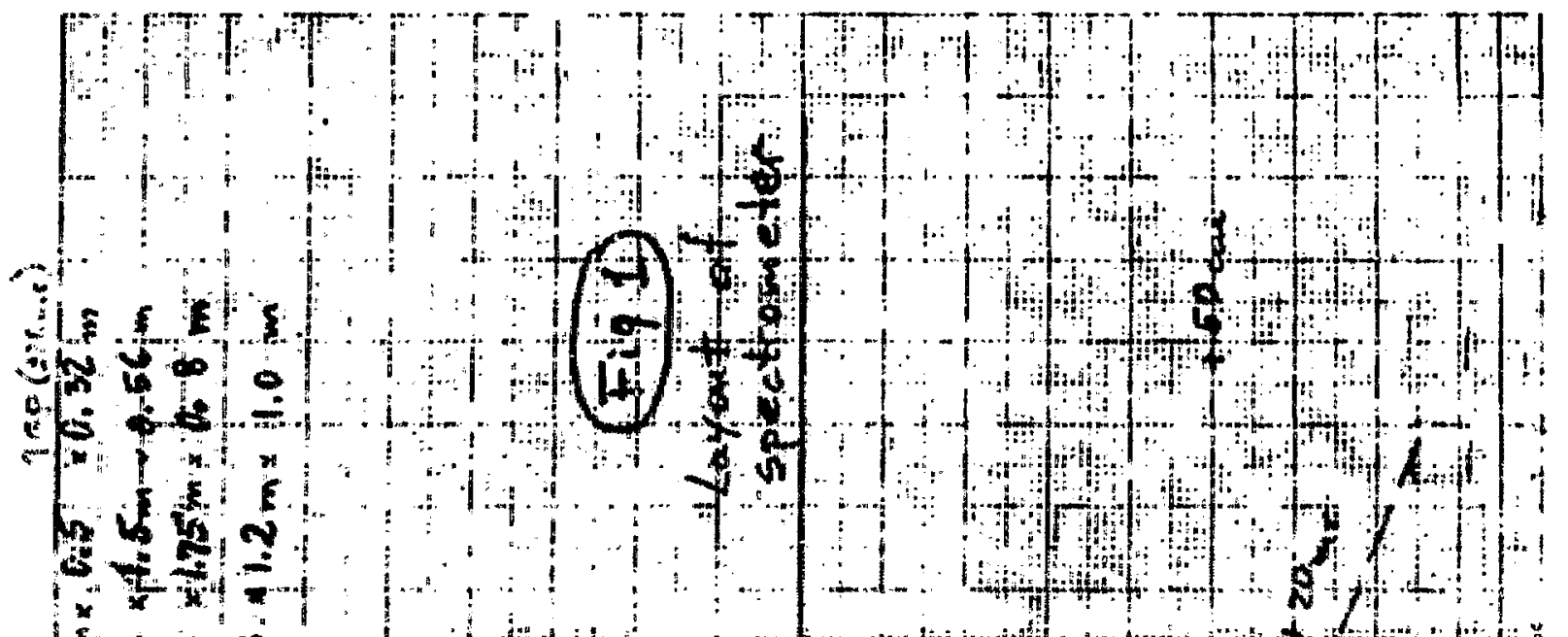

Lim

(a)

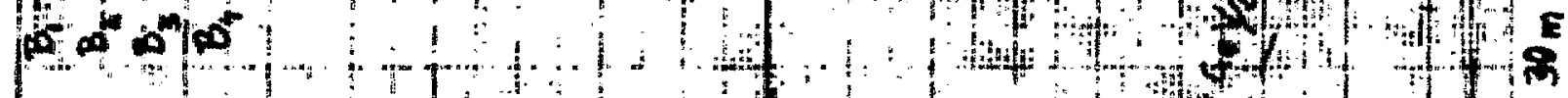

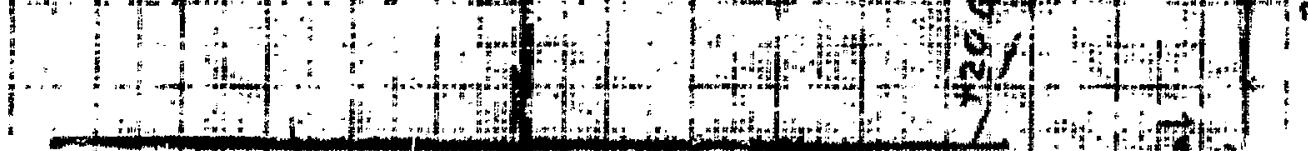

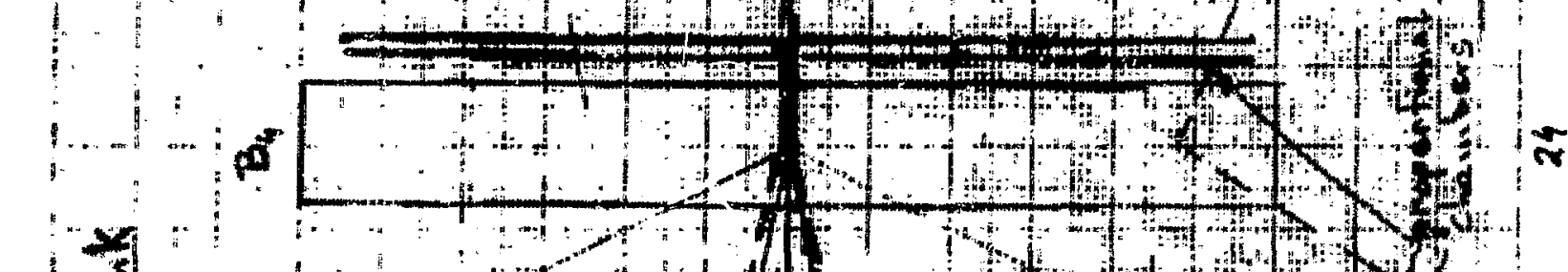

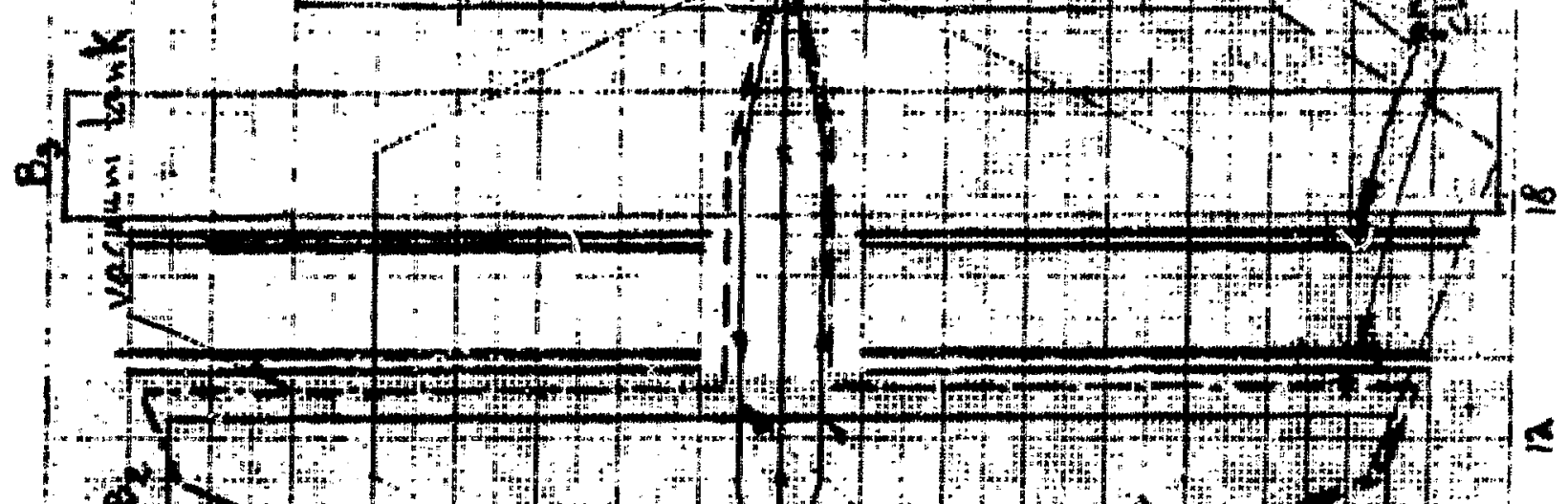

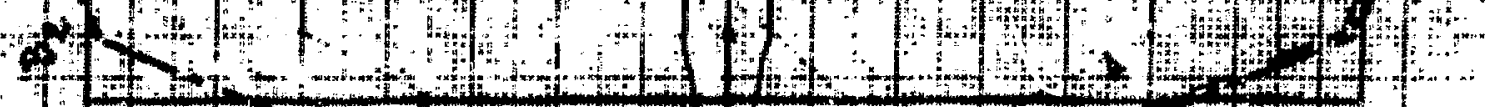

in

$\mid$ 


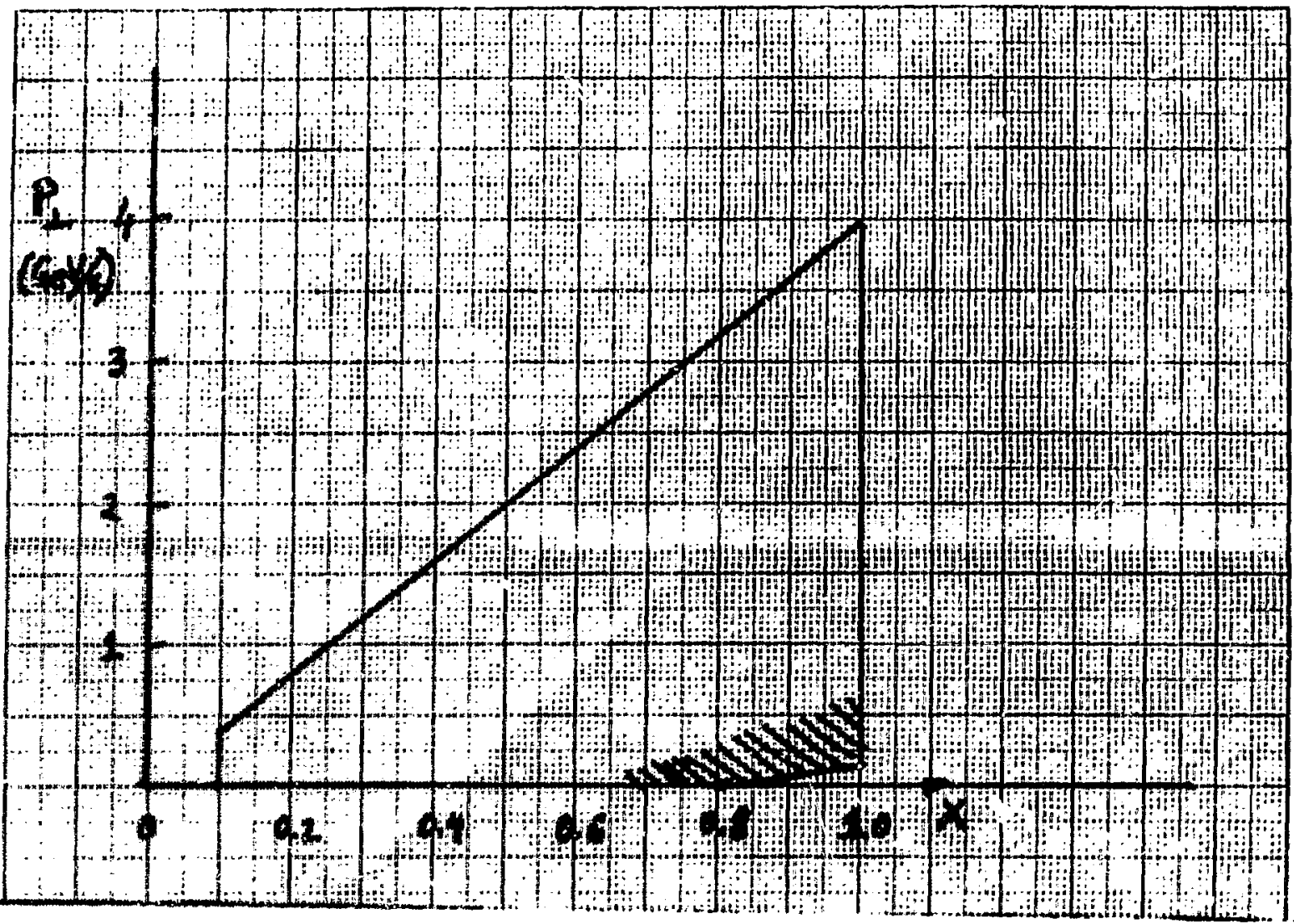

F1g. 2 .

Acceptance

Note: Inside wost of the polygon the acceptance is nearly $100 \%$.

There will by some losses dut to the partales crossing the beam plpe downstram of $\mathrm{B}_{2}$. These losses become appreclable

for the shaded regiton, and reach a maximum of SOX at the edge. 